\title{
ESTADOS DE ALARMA DE 2010 Y 2020 Y LAS LIMITACIONES SOBRE EL DERECHO DE HUELGA
}

\author{
María Dolores Martínez Cuevas \\ Profesora Titular de Derecho Constitucional, \\ Universidad de Granada
}

Cómo citar este artículo / Citation: Martínez Cuevas, M. D. (2021). Estados de alarma de 2010 y 2020 y las limitaciones sobre el derecho de huelga. Garrido López, C. (coord.)

Excepcionalidad y Derecho: el estado de alarma en España, Colección Obras colectivas, Fundación Manuel Giménez Abad, Zaragoza.

DOI: https://doi.org/10.47919/FMGA.OC21.0011

SUMARIO: I. INTRODUCCIÓN. II. ESTADO DE ALARMA DE 2010 Y LIMITACIONES SOBRE EL DERECHO DE HUELGA. III. ESTADO DE ALARMA DE 2020 Y LIMITACIONES DE DERECHOS: EN ESPECIAL SU INCIDENCIA SOBRE EL DERECHO DE HUELGA: 1. La crisis sanitaria de la COVID-19 y el dilema estado de alarma o estado de excepción. 2. Las limitaciones sobre algunos derechos y libertades fundamentales. 3. Las limitaciones sobre el derecho de huelga. A) Planteamiento. B) El derecho de huelga en circunstancias ordinarias. C) Estado de alarma de 2020 y su incidencia sobre el derecho de huelga. IV. ALGUNAS PROPUESTAS DE LEGE FERENDA Y DE CONSTITUCIÓN FERENDA: 1. Balance de lege ferenda a partir del estado de alarma de 2010 y su incidencia sobre el derecho de huelga. 2. Lecciones de lege ferenda del estado de alarma de 2020 y sus limitaciones sobre el derecho de huelga

"No sobrevive la especie más fuerte,

ni la más inteligente, sino la que mejor responde al cambio."

Charles Darwin 


\section{INTRODUCCIÓN}

En nuestro país se contempla, tal y como expusimos en un trabajo reciente: "un derecho de excepción garantista para evitar que se menosprecie nuestra Constitución ante situaciones emergentes o críticas que puedan poner en jaque nuestro Estado social y democrático de derecho"1. Este derecho de excepción previsto para restablecer la normalidad constitucional se contiene en los arts. 55 y 116 de nuestra Constitución (CE). En relación al art. $116 \mathrm{CE}$, su análisis "había estado huérfano de jurisprudencia ordinaria y constitucional por la sencilla razón de que no se había puesto a prueba ni nuestra Constitución ni la legislación de desarrollo constitucional en esta materia" ${ }^{2}$. El estado de alarma es el estado excepcional que menos gravedad representa en cuanto a los efectos y la duración. Lo declara el Gobierno, en todo o en parte de nuestro país, si concurre cualquiera de las modificaciones peligrosas de la "normalidad" previstas en el art. 3 de la LO 4/1981, de los estados de alarma, excepción y sitio (LOEAES) ${ }^{3}$.

Un precedente legislativo interesante de este estado extraordinario es "el estado de prevención de la Ley de Orden Público republicana de 1933, aunque a diferencia de este, el actual no prevé la suspensión de ningún derecho fundamental. Del art. 55.1 de nuestra Norma Fundamental se deduce que, si se declara el estado de alarma en nuestro país, no se puede suspender ningún derecho fundamental ni ninguna libertad pública, y entre ellos no se puede suspender el derecho fundamental a la huelga. Esto es una importante diferencia respecto a los estados de excepción y sitio"4.

En otro orden de consideraciones, la ubicación concreta del derecho fundamental de huelga en nuestra Carta Magna, dentro de la sección $1^{\text {a }}$ del capítulo $2^{\circ}$ del Título I de la CE 78 , lo convierte en uno de los más garantizados

\footnotetext{
${ }^{1}$ MARTÍNEZ CUEVAS, Ma. D. "El estado de alarma y el derecho fundamental de huelga: el caso de los controladores civiles de tráfico aéreo en España". Trabajo y Derecho: nueva revista de actualidad y relaciones laborales, núm. 64, 2020, p. 2.

2 Ibídem, pp. 2-3.

3 “a) Catástrofes, calamidades o desgracias públicas, tales como terremotos, inundaciones, incendios urbanos y forestales o accidentes de gran magnitud. b) Crisis sanitarias, tales como epidemias y situaciones de contaminación graves. c) Paralización de servicios públicos esenciales para la comunidad, cuando no se garantice lo dispuesto en los artículos veintiocho, dos y treinta y siete, dos, de la Constitución, y concurra alguna de las demás circunstancias 0 situaciones contenidas en este artículo. d) Situaciones de desabastecimiento de productos de primera necesidad."

${ }^{4}$ MARTÍNEZ CUEVAS, Ma. D., "El estado de alarma y el derecho fundamental de huelga: el caso de los controladores civiles de tráfico aéreo en España", op. cit., p. 4.
} 
de nuestro ordenamiento. Por ende, nuestra Constitución le dispensa la siguiente protección: a) una garantía jurisdiccional ordinaria (el procedimiento preferente y sumario de la ley 62/78) y una garantía jurisdiccional constitucional (el recurso de amparo constitucional), en virtud del art.53.2; b) dos garantías normativas, ya que, por una parte, su regulación se deberá de hacer mediante ley orgánica (art. 81.1) y, por otra parte, su reforma es tremendamente difícil, al estar superprotegido (art. 168.1).

Sea como sea, el derecho de huelga es uno de los derechos colectivos más limitados en nuestro ordenamiento jurídico. Incluso, se trata de un derecho que, en puridad, no es posible suspender si se declara el estado de alarma, aunque sí se puede suspender si se declara el estado de excepción, por lo que uno de los asuntos más controvertidos en nuestro trabajo radica en deslindar ambos fenómenos (suspensión y limitación de derechos).

Realizadas estas previas consideraciones, el primer interrogante que puede surgir al leer el título de este trabajo es pensar: ¿acaso existe alguna semejanza entre los estados de alarma de 2010 y de 2020 como para abordarlos conjuntamente en un mismo trabajo, bajo el prisma de la limitación del derecho de huelga? A priori, pudiera parecer que lo único que comparten ambos estados excepcionales es precisamente que han sido la primera y la segunda ocasión en que se ha declarado este estado ${ }^{5}$ en España tras la aprobación de la Constitución de 1978. Conscientes de los equívocos a los que puede conducir la denominación de esta investigación intentaremos dejar claro y razonar desde el primer momento que sí hay motivos para examinarlos a la vez.

En los estados de alarma de 2010 y de 2020, constata Garrido López "la tenue línea existente entre la limitación y la suspensión de derechos. [...] las insuficiencias de la LOAES en punto a la regulación de los supuestos habilitantes de la declaración podían ser superadas mediante una interpretación constitucionalmente conforme con la irreductible naturaleza bifronte del estado de alarma, instrumento útil a un tiempo ante catástrofes y crisis sanitarias y frente a ciertos conflictos sociales que, al no alterar

5 MARTÍNEZ CUEVAS, Mạ. D., La suspensión individual de derechos y libertades fundamentales en el ordenamiento constitucional español: un instrumento de defensa de la Constitución de 1.978. Editor: Editorial de la Universidad de Granada. D.L.: Gr. 296 - 2006. En el Capítulo I abordo "La defensa de la Constitución democrática en circunstancias extraordinarias. El derecho de excepción." Concretamente en las págs. 11 a 121. Tesis Doctoral defendida el 16 de enero de 1998. 
significativamente el orden público, no requieren la suspensión generalizada de derechos"6.

Sin embargo, sendos estados de alarma no son dos fenómenos asimilables para Fernández Rodríguez quien, desde su atalaya penalista, considera que el estado de alarma de 2010, se muestra de escasa eficacia para la situación actual que estamos padeciendo en 2020. En otros términos, la restricción reciente por el coronavirus es "clara, patente, notoria y manifiesta. $Y$ tal limitación de derechos fundamentales necesita una cobertura legal que solo tiene encuadre, según nuestra Constitución (art. 55.1), bajo la declaración del estado de excepción o de sitio. Nunca bajo el estado de alarma". En suma, lo que originariamente fue correcto (proclamar el estado de alarma para atajar la crisis sanitaria) ha evolucionado y debe avanzar hacia adelante, proclamando el estado de excepción, con el permiso previo de la Cámara Baja ${ }^{7}$.

En la senda administrativista Fernández de Gatta compara los estados de alarma de 2010 y de 2020, y pone sobre la mesa algunos problemas respecto a dos clases de fuentes normativas comunes en un estado excepcional como el de alarma: Primera, "el uso (y abuso, sin duda) de los Reales Decretos-Leyes", que cuentan con sustancia particular, al no estar sometidos al estado de alarma, ya que pueden aprobarse para cuestiones no conectadas al indicado estado. Segunda, destaca la cuestión de la reglamentación de algunos temas a través de decretos ministeriales, pues en determinados casos repercuten en documentos jurídicos, con enigmas "legales e incluso constitucionales".

\footnotetext{
${ }^{6}$ GARRIDO LÓPEZ, C., "La naturaleza bifronte del estado de alarma y el dilema limitaciónsuspensión de derechos", Teoría y Realidad Constitucional, núm. 46, 2020, p. 400.

${ }^{7}$ FERNÁNDEZ RODRÍGUEZ, J. J., "Cuestiones constitucionales sobre el estado de alarma en España y la pandemia del COVID-19", Instituto Español de Estudios Estratégicos, 1 de mayo de 2020, pp. 9, 12 y 13. Este autor ocupó en 2017 el Juzgado Central de Instrucción núm. 6 de la Audiencia Nacional. En sintonía con este penalista, C. MADRIGAL, la primera mujer que llegó a Fiscal General del Estado, en diciembre de 2014, y actual Fiscal de Sala del Tribunal Supremo, manifiesta que el actual Gobierno socialista de Pedro Sánchez trata de imponer "un auténtico estado de excepción". https://www.outono.net/elentir/2020/05/04/una-fiscal-delsupremo-acusa-al-gobierno-de-imponer-un-verdadero-estado-de-excepcion/

${ }^{8}$ FERNÁNDEZ DE GATTA SÁNCHEZ, D., "Los problemas de las medidas jurídicas contra el coronavirus: las dudas constitucionales sobre el Estado de Alarma y los excesos normativos". Diario La Ley, núm. 9641, de 27 de mayo de 2020, núm. 9641, 27 de may. de 2020, Editorial Wolters Kluwer, pp. 15 y 16.
} 


\section{ESTADO DE ALARMA DE 2010 Y LIMITACIONES SOBRE EL DERECHO DE HUELGA}

Refiriéndonos al primer estado de alarma, reflexionábamos en abril de 2020 que "en la España constitucional reciente, sólo se ha declarado en una ocasión el estado de alarma, y fue como respuesta a la huelga sin preaviso, no anunciada, calificada también como 'salvaje', y, como después demostraremos, ilegal, de los controladores civiles de tránsito aéreo en los aeropuertos españoles, el viernes 3 de diciembre de 2010, al inicio del largo puente que unía la festividad del día de la Constitución (lunes, 6 de diciembre) y de la Inmaculada Concepción (miércoles, 8 de diciembre). No era la primera vez que este colectivo privilegiado mostraba su malestar con sus condiciones laborales (básicamente el horario y el pago de las horas extraordinarias), pues, en realidad, se trataba de un viejo y oxidado conflicto laboral entre el sindicato de los controladores civiles de tránsito aéreo y la entidad pública empresarial Aeropuertos Españoles y Navegación Aérea (AENA), esta última tenía una posición de vulnerabilidad respecto a este colectivo"9.

A nuestro juicio, como ya expusimos, semejante "insistencia por parte de este Decreto en calificar la situación como 'calamidad pública de enorme magnitud' o como 'catástrofe pública', nos parece que se debía a que el Gobierno era consciente de que no se cumplía más que uno de los dos requisitos imprescindibles para declarar un 'estado de alarma', previstos en el art. 4 de la LO 4/1981. La letra a) de dicho precepto se refiere a una de ellos: 'catástrofes, calamidades o desgracias públicas, tales como terremotos, inundaciones, incendios urbanos y forestales o accidentes de gran magnitud'. Evidentemente, en el caso que nos ocupa sólo hubo un motivo, el de la letra c) del art. 4: 'Paralización de servicios públicos esenciales para la comunidad' sin garantizar lo contemplado en el art. 28.2 CE, al dejar de trabajar todo el colectivo de los controladores civiles aéreos sin cumplir ninguno de los requisitos exigidos para declarar una huelga"10.

Es más, sin duda, la "militarización de este gremio es una de las claves de este problema, resultando a la postre uno de los aspectos más controvertidos de esta declaración, pues los controladores aéreos en esta época eran un personal asimilado a los funcionarios públicos". El art. 12.2 de la LOEAES

\footnotetext{
${ }^{9}$ MARTÍNEZ CUEVAS, Mạ. D., "El estado de alarma y el derecho fundamental de huelga: el caso de los controladores civiles de tráfico aéreo en España", op. cit., p. 4.

${ }^{10}$ Ibídem, p. 6.
} 
dispone que en los casos recogidos "en las letras c) y d) del art. 4, cuando se declare un estado de alarma, el Gobierno 'podrá acordar la intervención de empresas o servicios, así como la movilización de su personal, con el fin de asegurar su funcionamiento'". Sin embargo, conforme al art. 117.5 CE, una vez declarado este estado "no es posible someter al personal a la jurisdicción militar, no es posible militarizarlos"11.

Como tuvimos ocasión de analizar, se recurrió ante el TC el Acuerdo del Pleno de la Cámara Baja, de 16 de diciembre de 2010, que permitió la prórroga de este estado de alarma, y al final se inadmitió por el ATC 7/2012 $2^{12}$. Interpretó nuestro TC que, en dicho Acuerdo, todas las decisiones parlamentarias asociadas al estado de alarma, es decir, la prórroga del estado de alarma, la previa autorización y prórroga del estado de excepción, la declaración del estado de sitio (y entendemos que su prórroga también), "no son meros actos de carácter 'autorizatorio', pues tienen un contenido normativo o regulador [...] todos ellos, decisiones con rango o valor de ley". Por ello, sentenció que la vía para que actúe la justicia constitucional y fiscalice estos "actos o decisiones" es el recurso de inconstitucionalidad, no el de amparo constitucional ${ }^{13}$.

Volviendo sobre este ATC, como ya manifestamos "si el constituyente primero y el legislador después hubiesen querido darles a estas normas el carácter de ley lo habrían contemplado expresamente, y esto no ha ocurrido, como sabemos. Es evidente que no se comenta nada en este Auto sobre la declaración del estado de alarma, sólo sobre su prórroga ${ }^{14}$.

Centrándonos ya en la huelga, nuestra Carta Magna es "pionera" en plasmar el derecho de huelga en España ${ }^{15}$, y sorprende bastante que cuando se estaba gestando en el Parlamento el precepto que lo regula (art. $28 \mathrm{CE}$ ), paralelamente se estaba implementando el RDL 17/1977, de 4 de marzo, sobre relaciones de trabajo, derogado en parte por la Ley $8 / 1980^{16}$, y declarado en

\footnotetext{
11 lbídem, p. 7.

12 Ibídem, pp. 7-8.

${ }^{13}$ ATC 7/2012, de 13 de enero de 2012. Inadmite a trámite el RAC 1598-2011, planteado por D. Pedro María Gragera de Torres y 321 personas más, controladores de tránsito aéreo al servicio de AENA, en relación con el acuerdo del Pleno del Congreso de los Diputados de 16 de diciembre de 2010, de autorización de la prórroga del estado de alarma. FFJJ $3^{\circ}$ y $4^{\circ}$.

${ }^{14}$ MARTÍNEZ CUEVAS, Ma․ D., "El estado de alarma y el derecho fundamental de huelga: el caso de los controladores civiles de tráfico aéreo en España”, op. cit., p. 7.

${ }^{15}$ Ibídem, p. 9.

${ }^{16}$ Ley 8/1980, de 10 de marzo, del Estatuto de los Trabajadores (BOE núm. 64, 14 de marzo de 1980).
} 
parte inconstitucional un año después, mediante la STC $11 / 1981^{17}$. Por ende, la concreción jurídica del art. 28 CE se llevó a cabo conforme a "una ley preconstitucional aunque no inconstitucional, una norma jurídica claramente desfasada, entre otras razones por haber pasado ya 43 años desde su publicación en un contexto laboral, jurídico, político, sociológico y económico muy diferente al que vivimos en la actualidad"18.

Obviamente, otra de las cuestiones controvertidas radica en averiguar "si la adecuada respuesta a una huelga de este tipo, que afectó gravemente al tráfico aéreo en pleno puente de la Constitución, fue declarar el estado de alarma. 0 si, por el contrario, esta proclamación fue totalmente desproporcionada (llegando a movilizar y/o militarizar al colectivo de controladores civiles) e inoportuna (por la imagen de debilidad e impotencia que ofreció España ante el mundo, frente a este colectivo de trabajadores, el mejor pagado de toda Europa), y lo que es más grave, si puede llegar a calificarse de inconstitucional esta declaración del estado de alarma" ${ }^{19}$. Esta incógnita que se ha planteado se despeja en las conclusiones del presente trabajo.

Finalmente, una breve comparación entre Alemania y España nos pone de relieve que, los perjudiciales efectos personales y económicos acaecidos en nuestro país, en el puente festivo de diciembre de 2010, "por la huelga de los controladores aéreos con más de 4.500 vuelos cancelados que afectaron alrededor de 650.000 pasajeros y con una pérdida económica de más de 200 millones de euros" ${ }^{20}$, son análogos a los ocasionados en el país germánico, durante la gélida estación invernal de 2017, allí "los pilotos civiles de la

${ }^{17}$ STC 11/1981, de 8 de abril de 1981. Pleno. Recurso de inconstitucionalidad 192/1980 (BOE núm. 99, 25 de abril de 1981). Declara inconstitucional los arts. 25.b y 26 y ha interpretado los arts. 3; 5.1, 6.7, 10 y 11.b.

${ }^{18}$ MARTÍNEZ CUEVAS, Ma. D., "El estado de alarma y el derecho fundamental de huelga: el caso de los controladores civiles de tráfico aéreo en España", op. cit., p. 9. Ya expusimos en este trabajo que existió "un intento de desarrollar legislativamente el art. 28 de la Constitución, pues en 1992, como sabemos, se planteó un Proyecto de Ley Orgánica de Huelga para regular los servicios esenciales y los servicios mínimos bajo el gobierno socialista presidido por Felipe González Márquez, aunque se quedó en un Proyecto que se aprobó en el Congreso, pasó al Senado y en el trámite de las enmiendas se devolvió al Congreso de nuevo, pero antes de que se aprobase definitivamente se convocaron elecciones anticipadas y el Parlamento fue disuelto al convocarse elecciones generales."

${ }^{19}$ Ibídem, p. 9.

${ }^{20}$ Al respecto, téngase en cuenta la reciente STJUE de 17 de abril de 2018 (asunto C-195/17 y acumulados), con recordatorio previo del conflicto acaecido en España los días 3 y 4 de diciembre de 2010. 
compañía aérea de Lufthansa bajo las siglas del sindicato Vereinigung Cockpit (VC) no volaron", dejando de transportar a más de 500.000 personas $^{21}$.

III.ESTADO DE ALARMA DE 2020 Y LIMITACIONES DE DERECHOS: EN ESPECIAL SU INCIDENCIA SOBRE EL DERECHO DE HUELGA

\section{La crisis sanitaria de la COVID-19 y el dilema estado de alarma o estado de excepción.}

Desgraciadamente en nuestro país, en los últimos cien años ha habido que lamentar una serie de circunstancias sanitarias extremas, siendo la más lejana la mal denominada gripe española en los años 1918 y 1919, a la que le siguió en 1981 el caso del síndrome del aceite de colza o la crisis sanitaria conocida como de las vacas locas en 2000, entre otras muchas. Estamos totalmente de acuerdo con Aparicio de Lázaro, en que el caso de la colza es muy similar a la crisis actual del covid-19, al menos en los siguientes aspectos: "decenas de miles de afectados y millares de fallecidos; la tardanza por parte de las autoridades sanitarias en la adopción de las medidas necesarias; la falta de unidad política, con el trasfondo de una situación social muy grave, repleta de desafíos y amenazas; el miedo en la población"22.

En circunstancias extraordinarias como las que estamos atravesando hace casi un año, ¿quedaría afectado nuestro sistema de fuentes por la ordenación jurídica del derecho de huelga? Este derecho constitucional está supeditado a "un complejo sistema de fuentes", como reconocen los profesores Ituren y Esteve, afirmando la existencia de una modificación de este sistema, provocada por el decreto que aprueba el vigente estado de alarma ${ }^{23}$. Una vez decretado este estado, mediante el Real Decreto 463/2020, de 14 de marzo ${ }^{24}$, y puesto que no se puede suspender ningún derecho fundamental (como el de

${ }^{21}$ MARTÍNEZ CUEVAS, Ma. D. "El estado de alarma y el derecho fundamental de huelga: el caso de los controladores civiles de tráfico aéreo en España", op. cit., p. 9.

${ }_{22}$ APARICIO DE LÁZARO, J. R., "Los estados de alarma y excepción como mecanismos legales ante una pandemia." Actualidad administrativa. 2020, núm. 5 (mayo). p. 27. https://www.smarteca.es/my-library/issues/SMTA558 (visitada el 10 de septiembre de 2020).

${ }^{23}$ ESTEVE SEGARRA, A. e ITUREN OLIVER, A., "El derecho de huelga en tiempos del estado de alarma por el COVID-19", Trabajo y Derecho, núm. 65 (mayo 2020), Editorial Wolters Kluwer. pp. 3 y 7.

${ }^{24}$ Real Decreto 463/2020, de 14 de marzo, por el que se declara el estado de alarma para la gestión de la situación de crisis sanitaria ocasionada por el COVID-19. BOE núm. 67, de 14 de marzo de 2020. 
huelga), "el régimen jurídico de su ejercicio es mucho más inseguro pues se puede producir una afectación por la exigencia de confinamiento de la población y las posibilidades de que el personal de determinados sectores sea movilizado. En efecto, la posibilidad de establecer medidas de movilización en el estado de alarma o la posibilidad de instituir servicios extraordinarios para los empleados públicos plantea problemas por la afectación del derecho de huelga"25.

Este Real Decreto 463/2020, del Consejo de Ministros que declara el estado de alarma, se ha prorrogado por el Congreso de los Diputados en numerosas ocasiones $^{26}$, la última vez ha sido en noviembre de 2020 y se aprueba una extensión de seis meses, desde el 9 de noviembre de 2020 hasta el 9 de mayo de $2021^{27}$.

Respecto al ingente uso del Derecho durante esta pandemia, no parece exagerado afirmar que ha habido un antes y un después en materia jurídica. Así es, el desproporcionado número de normas fue tildado en mayo de 2020 de "bosque de 209 normas excepcionales" ${ }^{28}$. A día de hoy podemos asegurar que este "bosque" ha crecido notablemente hasta el punto de que se ha convertido en una extensa selva de normas, casi impenetrable. Es más, el asimétrico ${ }^{29}$ empleo de los Decretos-Leyes durante esta crisis sanitaria y económica ha llevado a reflexionar a un constitucionalista como Teruel Lozano en "el acierto del 'doble' régimen" empleado, por lo que estas normas jurídicas sirven para afrontar las secuelas "sociales, laborales, económicas y a ciertas reformas administrativas puntuales necesarias a consecuencia de la crisis", llegando a ser así un tipo de disposiciones jurídicas de "acompañamiento". Por tanto, a su

${ }^{25}$ ESTEVE SEGARRA, A., e ITUREN OLIVER, A., "El derecho de huelga en tiempos del estado de alarma por el COVID-19", op. cit., p. 5.

${ }^{26}$ RUIZ ROBLEDO, A., "Razones jurídicas para una prórroga corta". Publicado en El Español, el 19 de mayo de 2020. RUIZ ROBLEDO, A., "El estado de alarma: donde quieren los gobernantes". Artículo publicado en El País, el 6 de noviembre de 2020.

${ }_{27}$ Art. 2 del Real Decreto 956/2020, de 3 de noviembre, por el que se prorroga el estado de alarma declarado por el Real Decreto 926/2020, de 25 de octubre, por el que se declara el estado de alarma para contener la propagación de infecciones causadas por el SARS-CoV-2. «BOE» núm. 291, de 4 de noviembre de 2020.

${ }^{28}$ RINCÓN, R., "Un bosque de 209 normas excepcionales." El País, 17 de mayo de 2020. EL PAíS @MIUI| https://elpais.com/espana/2020-05-16/el-estado-de-alarma-un-bosque-de-209normas-excepcionales.html

${ }^{29} A B C, 28$ de diciembre de 2020: "El Gobierno ningunea al Congreso: un decretazo cada diez días.", p. 10. 
juicio, el Ejecutivo estatal y el autonómico no han atropellado los Decretos-Leyes durante esta pandemia, con algunas salvedades específicas ${ }^{30}$.

En esta nueva era a la que asistimos incrédulos y expectantes se ha instalado cómodamente entre nosotros una expresión que parece que hubiese llegado para quedarse: "la nueva normalidad", que se ha puesto en cuarentena puesto que es manejada socialmente de forma "acrítica [...] como si las palabras no fueran peligrosas" ${ }^{\prime 1}$.

En otro orden de consideraciones, Alegre Ávila aboga por averiguar las opciones que la normativa común y corriente presenta de cara a su aplicación durante la pandemia ${ }^{32}$. Concretamente, la Ley 14/1986, de 25 de abril, General de Sanidad (LGS) y la Ley 3/1986, de 14 de abril, de medidas especiales en materia de salud pública (LOMESP). En la misma línea sobresale Villar Crespo, quien, en relación con estas últimas normas mencionadas, expone el contraste entre "un Derecho constitucional de excepción" y "un 'Derecho legal de necesidad', de corte informal y tremendamente flexible. Tal dicotomía no es otra que la existente entre libertad y seguridad, entre derechos fundamentales y autoridad"33. A mayor abundamiento, el constitucionalista García Vitoria plasma los interrogantes genéricos que presenta "la existencia de tres regímenes jurídicos (normalidad, estado de alarma y estado de excepción)"34.

Indudablemente, otro de los temas controvertidos y complejos, a efectos de esta investigación, radica en diferenciar entre suspensión y limitación de derechos, ya que durante el estado de alarma los artículos 55.1 y 116 CE no permiten, en sentido estricto, la suspensión de ningún derecho, sólo la

30 TERUEL LOZANO, G., "Los decretos-leyes en la crisis del coronavirus: perspectiva constitucional". Cuadernos Manuel Giménez Abad. M. 8 (jun. 2020). (10 p.) Obtenido en la URL https://www.fundacionmgimenezabad.es/es/publicaciones?field_tipo_value $=1 \&$ title $=$ (visitada el 14 de julio de 2020).

31 GONZÁLEZ DE LARA MINGO, S., "Hacia la era de la «nueva anormalidad» jurídica instaurada por la vía del uso de los Reales Decretos y las Órdenes Ministeriales". Diario La Ley, núm. 9649, de 9 de junio de 2020, núm. 9649, 9 de jun. de 2020, Editorial Wolters Kluwer, pp. 1 y 15.

32 ALEGRE ÁVILA, J. M., y SÁNCHEZ LAMELAS, A., "Nota en relación a la crisis sanitaria generada por la actual emergencia vírica", $A E L P A$ http://www.aepda.es/AEPDAEntrada-2741-Nota-en-relacion-a-la-crisis-sanitaria-generada-porla-actual-emergencia-virica.aspx

${ }^{33}$ VILLAR CRESPO, G., "Repensando el derecho de excepción: la crisis del coronavirus y los tres aprendizajes sobre el derecho de necesidad en el ordenamiento jurídico español". Revista General de derecho administrativo, núm. 54 (mayo 2020), pp. 47-48. https://www.iustel.com/default.asp. (visitada el 5 de junio de 2020).

${ }^{34}$ GARCÍA VITORIA, I., "El estado de alarma, los derechos fundamentales y los derechos laborales." Trabajo y Derecho, Monográfico 12/2020, núm. 12, 1 de nov. de 2020, Editorial Wolters Kluwer, p. 1. 
limitación de los mismos. Profundizando en esta dicotomía (suspensión/limitación), entiende Cotino Hueso que se debe utilizar si se produce desde la óptica formal "la suspensión bajo los presupuestos constitucionales, se altera el régimen de fuentes de los derechos y se habilita a diferentes reguladores para que los derechos puedan ser más intensamente restringidos de lo que sería constitucionalmente admisible en una situación ordinaria". Materialmente los "elementos básicos de control de la admisibilidad de la restricción de un derecho pueden quedar muy desdibujados a partir de un canon de control muy laxo (justificación objetiva, razonable y proporcionalidad). Ello no obsta para que se mantengan generalmente las garantías de razonabilidad vinculada a la no arbitrariedad y proporcionalidad y que en todo caso, pese a que no se mantenga el contenido esencial, se postulen unos mínimos a respetar"35.

Obviamente, una de las claves para afrontar esta crisis sanitaria sería saber si debería haberse declarado el estado de alarma o el de excepción. Al respecto, la panoplia de respuestas doctrinales es amplia. Así, por ejemplo, arguye Fernández Rodríguez que la declaración del estado de alarma es el instrumento normativo-constitucional adecuado ya que declarar la excepción sirve para "alteraciones de orden público, no para crisis de salud". También considera que eran inoportunas otras soluciones como declarar el estado de excepción o el de sitio, o aplicar la legislación sanitaria ordinaria ${ }^{36}$. Al respecto, García Vitoria baraja el dilema de afrontar la crisis sanitaria aprobando alguno de los estados excepcionales, o bien con la legislación sanitaria ordinaria. Este profesor deduce que declarar la alarma es un mecanismo útil e indispensable, mientras que la disyuntiva de afrontar la quiebra sanitaria mediante la normativa ordinaria contemplada para situaciones emergentes, puede conducir a circunstancias a medio camino entre la excepcionalidad y "la normalidad constitucional, que no quedan cubiertas ni por las garantías constitucionales ordinarias"37.

${ }^{35}$ COTINO HUESO, L., "Los derechos fundamentales en tiempos del Coronavirus. Régimen general y garantías y especial atención a las restricciones de excepcionalidad ordinaria.", El Cronista, núm. 86-87, IUSTEL, monográfico Coronavirus... y otros problemas, marzo-abril 2020, pp. 92 y 93. Acceso particular en Academia, todo el número en http://www.elcronista.es/El-Cronista-n\%C3\%BAmero-86-87-Coronavirus.pdf

${ }^{36}$ FERNÁNDEZ RODRÍGUEZ, J. J., "Cuestiones constitucionales sobre el estado de alarma en España y la pandemia del COVID-19", op. cit., p. 10.

${ }^{37}$ GARCÍA VITORIA, I., "El estado de alarma, los derechos fundamentales y los derechos laborales.", op. cit., pp. 1 y 16 . 
Apremia cambiar la LOEAES, a juicio de Garrido López, para "recuperar la relación meramente enunciativa de los supuestos habilitantes del estado de alarma, asumir su naturaleza bifronte y clarificar su operatividad en situaciones de conflictividad social. [...] Es el momento idóneo para estudiar y acometer esta reforma. El estado de alarma no es una amenaza, sino una garantía extraordinaria que, en circunstancias críticas, evita la improvisación y la inseguridad jurídica. Desterremos la demonización que este instrumento padece por motivos exclusivamente políticos, reconozcamos su utilidad y aprovechemos las lecciones que la crisis de la COVID-19 proporciona para mejorarlo"38.

En este punto de la investigación, sorprende la original y novedosa solución ofrecida por el constitucionalista Ruiz Miguel (declaración simultánea de ambos estados, alarma y excepción), ya que, a su parecer, si se producen a la vez "esos supuestos de hecho diferentes lo procedente sería intentar declarar simultáneamente ambos estados 0 , al menos, intentar que ambos puedan tener vigencia simultánea. De haberse seguido esta vía que, a nuestro juicio, era la correcta, no se hubiese planteado el problema de una declaración del estado de alarma incluyendo contenidos (suspensión de determinados derechos) propios del estado de excepción" ${ }^{39}$.

No resulta sencillo deslindar los estados de alarma y de excepción, por eso compartimos el juicio que realiza el constitucionalista Solozábal Echavarría, pues puede ocurrir que "la crisis contemplada a priori en el estado de alarma se convierta en una quiebra del orden público", especialmente teniendo en cuenta la jurisprudencia constitucional ${ }^{40}$. Llegados a este punto, una interpretación similar nos la ofrece Rodríguez Fernández, para quien, aunque en un principio "era correcto la declaración del estado de alarma para hacer frente a esta pandemia, ha ido derivando a un problema de orden público al limitarse el libre ejercicio de los derechos y libertades fundamentales de los ciudadanos que

${ }^{38}$ GARRIDO LÓPEZ, C., "La naturaleza bifronte del estado de alarma y el dilema limitaciónsuspensión de derechos", Teoría y Realidad Constitucional, núm. 46, 2020, p. 401.

39 RUIZ MIGUEL, C., "Crisis del Coronavirus y crisis del Estado constitucional español." [Recurso electrónico]. (25 p.). Obtenido de la URL https://www.smarteca.es/mylibrary/issues/SMTA5972 (visitada el 19 de junio de 2020), p. 21.

40 SOLOZABAL ECHAVARRIA, J. J., "Algunas consideraciones constitucionales preliminares sobre el estado de alarma (fragmento)". Fecha de publicación: oct 05, 2020 http://www.cepc.gob.es/cepc/blog 
solo [sic] pueden verse suspendidos por la declaración del estado de excepción" ${ }^{41}$.

A pesar de todo, hay autores que contra todo pronóstico entienden que lo que existe en la actualidad, ya que no se ha decretado la excepción, es "una aplicación de la técnica de suspensión de los derechos fundamentales individualizada del artículo 55.2 de la Constitución, que solamente cabe, ex artículo 55.2 CE, de forma individual y con la necesaria autorización judicial”42.

En este contexto, existe un manual aprobado en el Consejo de Europa y dirigido a los poderes públicos al que alude Queralt Jiménez, cuando ciertos Estados miembros proponen al Secretario de esta institución su voluntad de revocar la vigencia del Convenio Europeo de Derechos Humanos (en adelante $\mathrm{CEDH})^{43}$. Todo ello en aplicación de lo dispuesto en el artículo 15 del $\mathrm{CEDH}^{44}$ (derogación en caso de estado de excepción). Algunos de los factores de esta guía del CEDH son las informaciones que circulan "por las redes y los medios [que] pueden fomentar la propagación del virus y evitar la correcta curación; pero, también, hacer los sistemas políticos más vulnerables”. De ahí que el Consejo de Europa califica a estos medios de comunicación de factores determinantes para "contrarrestar esta infodemia, y les exige una responsabilidad especial para ofrecer información veraz y confiable". Incluso, en las circunstancias excepcionales que vivimos, estos medios de comunicación colaborarán en la no difusión de determinadas acciones que el Gobierno disponga hasta que lo considere idóneo ${ }^{45}$.

\footnotetext{
${ }^{41}$ RODRÍGUEZ FERNÁNDEZ, P., “¿Estado de Alarma o Estado de Excepción?” (1) [Recurso electrónico] / Diario La Ley. A. 40, núm. 9627 (7 mayo 2020). 15 p.

42 FERNÁNDEZ FONTECHA, M., "La excepción y el derecho." Tribuna El Derecho. Publicado el 31 de marzo de 2020, https://elderecho.com/la-excepcion-derecho

${ }^{43}$ Este Manual se denomina Respecting democracy, rule of law and human rights in the framework of the COVID-19 sanitary crisis. A. QUERALT JIMÉNEZ, "El coronavirus, 'test de estrés' al Estado de Derecho." https://www.fundacionmgimenezabad.es/es/el-coronavirus-testde-estres-al-estado-de-derecho

${ }^{44}$ Veamos el tenor literal del art. 15 del CEDH: "1. En caso de guerra o de otro peligro público que amenace la vida de la nación, cualquier Alta Parte Contratante podrá tomar medidas 1415 que deroguen las obligaciones previstas en el presente Convenio en la estricta medida en que lo exija la situación, y a condición de que tales medidas no estén en contradicción con las restantes obligaciones que dimanan del derecho internacional. 2. La disposición precedente no autoriza ninguna derogación del artículo 2, salvo para el caso de muertes resultantes de actos lícitos de guerra, ni de los artículos 3, 4 (párrafo 1) y 7. 3. Toda Alta Parte Contratante que ejerza este derecho de derogación tendrá plenamente informado al Secretario General del Consejo de Europa de las medidas tomadas y de los motivos que las han inspirado. Deberá igualmente informar al Secretario General del Consejo de Europa de la fecha en que esas medidas hayan dejado de estar en vigor y las disposiciones del Convenio vuelvan a tener plena aplicación."

${ }^{45}$ QUERALT JIMÉNEZ, A., “El coronavirus, 'test de estrés' al Estado de Derecho.”, op. cit.
} 


\section{Las limitaciones sobre algunos derechos y libertades fundamentales}

Aunque el objeto de nuestra investigación se centra en cómo incide el estado de alarma en el derecho fundamental de huelga, vamos a abordar de forma tangencial cómo han quedado afectados por esta situación anómala e inusual otros derechos y libertades fundamentales:

\section{A) Libertad de circulación}

El Abogado del Estado Leiva Escudero, acalla las ideas que afirman la existencia de un "estado de excepción encubierto" y propugna que estas decisiones son constitucionales y legales. Estos recortes, pese a que impactan en el "contenido esencial" de la libertad de circulación, no significan su suspensión. Por ende, son legales las decisiones de limitación de la libertad de circulación contempladas en el art. 7 del RD 463/2020, declarando el estado de alarma. A esta tesis llega tras estudiar la figura de la suspensión a la luz, tanto del tratamiento jurídico-constitucional e internacional (CEDH), como de la jurisprudencia constitucional, e infiere que esas decisiones se podrían tomar con la cobertura de la normativa de sanidad ordinaria ${ }^{46}$. A una conclusión diametralmente opuesta llega Enríquez Malavé, también Abogado del Estado, quien valora que el citado precepto no sería constitucional, al contemplar por un lado restricciones "al contenido esencial de un derecho fundamental sin tener naturaleza de ley orgánica, innovando límites a la libertad de circulación", no establecidos en la LOEAES ${ }^{47}$.

\section{B) Libertad de culto y libertad religiosa}

De algún modo, la libertad religiosa prevista en el art. 16 CE ha quedado afectada por el estado de alarma. En este contexto, para Fernández de Gatta,

${ }^{46}$ LEIVA ESCUDERO, G., "Constitucionalidad de las restricciones a la libertad de circulación en el estado de alarma por el coronavirus Covid-19." [Recurso electrónico] 1 fichero PDF (19p.) Diario La Ley, núm. 9642, de 28 de mayo de 2020, Editorial Wolters Kluwer. Obtenido de la URL https://diariolaley.laleynext.es/content/Inicio.aspx (visitada el 28 de julio de 2020), pp. 1 y 18.

${ }^{47}$ ENRÍQUEZ MALAVÉ, G., "Inconstitucionalidad de las limitaciones a la libertad de circulación establecidas en el Real Decreto 463/2020, de 14 de marzo, por el que declara el estado de alarma para la gestión de la situación de crisis sanitaria ocasionada por el COVID-19". [Recurso electrónico] 1 fichero PDF (11 p.). Diario La Ley, núm. 9620, de 24 de abril de 2020, Editorial Wolters Kluwer. Obtenido de la URL https://diariolaley.laleynext.es/content/Inicio.aspx (visitada el 3 de junio de 2020), pp. 1 y 11. 
el no poder realizar conmemoraciones "religiosas" se contempla en la Orden SND/298/2020, de 29 de marzo, hasta que se pusiese fin al estado de alarma. Es más, se restringe el número de personas que pueden participar 0 acompañar la inhumación o la partida, antes de incinerar al difunto, con la obligación de mantener una separación de uno a dos metros entre ellos. El referido autor pone el foco en cómo repercute la declaración del vigente estado de alarma en la libertad religiosa del art. $16 \mathrm{CE}$, especialmente el art. 7 de la citada declaración, que veta la libertad de circulación para imposibilitar la libertad de culto, y ello ha acontecido en algunas conmemoraciones católicas y en diferentes núcleos urbanos, aunque le sorprende que se hayan podido celebrar determinados ritos y conmemoraciones de otras religiones ${ }^{48}$.

\section{C) Privacidad y protección de datos}

La Inteligencia Artificial (IA) y el big data, no han tenido éxito ni para afrontar el coronavirus ni para prevenir "confinamientos y otras restricciones de derechos", según expone Cotino Hueso en un pormenorizado y exhaustivo estudio. La IA puede resultar sumamente eficiente y práctica para incrementar la "información ciudadana y de salud, la telemedicina y la mejor asignación de los recursos humanos y materiales". Representa un serio peligro para la intimidad el avance de aplicaciones, "pasaportes biológicos electrónicos o sistemas de geolocalización, trazabilidad y monitoreo de personas" realizados para combatir la covid-1949. Y concluye que la "anonimización" es básica, aunque será necesario ejecutar el sistema de salvaguarda de información personal, su reserva y la valoración de sus consecuencias ${ }^{50}$. En otra publicación este constitucionalista aprecia que del país asiático donde se ha originado esta pandemia (China), también procede el peligro del control digital intensivo. Sin olvidar que este proceso se ha de realizar con todas las garantías y protecciones disponibles ${ }^{51}$.

\footnotetext{
48 FERNÁNDEZ DE GATTA SÁNCHEZ, D., "Los problemas de las medidas jurídicas contra el coronavirus: las dudas constitucionales sobre el estado de Alarma y los excesos normativos", op. cit., p. 17.

${ }^{49}$ COTINO HUESO, L., "Inteligencia artificial, big data y aplicaciones contra el Covid y la privacidad y protección de datos", Revista Internet, Derecho y Política, IDP (abril-octubre), núm. 31, 2020, p. 1. El artículo completo está disponible en:

https://www.raco.cat/index.php/IDP/article/view/373681/467288

${ }^{50}$ lbídem, pp. 1, 12 y 13.

${ }^{51}$ COTINO HUESO, L., "Inteligencia Artificial y vigilancia digital contra el Covid-19 y contra la privacidad. El diablo está en los detalles." Documento de Opinión IEEE 36/2020. 
En este terreno, también hace hincapié en el uso de instrumentos científicos, como la geolocalización y la tecnovigilancia para atajar la actual epidemia sanitaria, Rodríguez Laínz, y reflexiona que pese a su "gran utilidad [...], su evidente colisión con derechos del entorno de la privacidad, y en concreto de la protección de datos personales, impone un riguroso análisis de las normas jurídicas en las que se basa su empleo, más allá de aquellos supuestos en los que se obtiene el consentimiento expreso de los interesados"52. Afirma Troncoso Reigada que carece de lógica que "los datos de geolocalización puedan ser objeto de tratamiento para garantizar bienes constitucionales como la seguridad nacional, la defensa, la seguridad pública o la prevención y persecución de delitos y no para garantizar otro bien constitucional relevante como es la salud pública" 53 .

De esta protección de los datos personales en el seno del Consejo de Europa, se ha ocupado la constitucionalista Queralt Jiménez, para quien asistimos a un tema controvertido, que se ha incrementado, puesto que ciertos Estados integrantes del mencionado Consejo han comenzado a emplear utensilios científicos para combatir esta crisis sanitaria. Junto a temores vinculados a esta grave dificultad sanitaria, en determinados segmentos sociales intranquiliza bastante la utilización que pueda experimentar su información privada ${ }^{54}$.

\section{D) Derechos de reunión y de manifestación}

En nuestro país, la declaración del estado de alarma ha implicado un grave recorte de la libertad de circulación para Carmona Contreras, aunque además ha comprobado la forma en que el disfrute y desarrollo de otros derechos

http://www.ieee.es/Galerias/fichero/docs_opinion/2020/DIEEEO36_2020LORCOT_CovidDigital. pdf (consultado el 17 de diciembre de 2020).

${ }^{52}$ RODRÍGUEZ LAINZ, J. L., "Medidas tecnológicas de control epidemiológico de pandemias: geolocalización y Tecnovigilancia." Diario La Ley, 24 de Mayo de 2018, Wolters Kluwer, p. 1. Las cursivas no son nuestras. En el siguiente enlace está disponible este artículo: https://diariolaley.laleynext.es/Content/Documento.aspx?params=H4sIAAAAAAAEAMtMSbF1C TEAAmMDS0MLS7Wy1KLizPw8WyMDIwMDE2MDkEBmWqVLfnJIZUGqbVpiTnEqAK1Y9T01 AAAAWKE\#tDT0000309189_NOTA49

53 TRONCOSO REIGADA, A., "Los tratamientos de datos personales para fines de salud pública y el derecho a la protección de datos personales en tiempos del COVID-19". Retos jurídico-éticos ante la crisis del Covid-19: perspectiva interdisciplinar, Wolters Kluwer, Madrid, 2020 , p. 599.

${ }^{54}$ QUERALT JIMÉNEZ, A., "El coronavirus, 'test de estrés' al Estado de Derecho.”, op. cit. 
relacionados con la libertad de circulación, específicamente los de reunión y manifestación, han sido cuestionados en la praxis ${ }^{55}$.

Precisamente, una vez decretado el estado de alarma, el derecho de manifestación no se puede suspender, y la clave constitucional radica en fijar el procedimiento y el modo en que su disfrute puede estar perjudicado por las restricciones impuestas a la libertad para desplazarse y moverse. Del mismo modo, el trayecto planteado es determinante, puesto que este no podrá realizarse por "vías neurálgicas" del término municipal, y así evitar "un colapso circulatorio" que ocasione que no se pueda llegar a ciertos sitios estratégicos para garantizar "servicios esenciales", como los hospitalarios. Si se sigue por esta senda que controla el peligro de infección, el disfrute de los derechos de manifestación y reunión es constitucional mientras esté en vigor el estado de alarma $^{56}$.

Indudablemente, se intenta ofrecer una explicación del por qué los derechos de reunión y manifestación han resultado afectados, basándose en el miedo "político" a que se pueda declarar el correcto estado extraordinario, y ha conducido a remedios cuyo engranaje normativo es controvertido ${ }^{57}$.

Las decisiones del TC (Auto de 30 de abril de 2020) en relación con los derechos que ahora nos ocupan se han examinado por el coordinador del Observatorio de Derecho Público y Constitucional y Covid-19 ${ }^{58}$, quien aprecia que nuestro supremo intérprete constitucional "confinado parece afirmar la constitucionalidad del estado de alarma y señala que para prohibir manifestaciones hay que analizar cada caso concreto" ${ }^{59}$. También se cuestiona la constitucionalidad del RD $463 / 2020^{60}$ al hilo del examen de los derechos de reunión y manifestación.

${ }^{55}$ CARMONA CONTRERAS, A. M., "Estado de alarma y derecho de manifestación en España" https://www.fundacionmgimenezabad.es/es/estado-de-alarma-y-derecho-de-manifestacion-enespana Publicado el martes, 5 de mayo, 2020.

${ }^{56}$ Ibídem.

${ }^{57}$ COTINO HUESO, L., "Confinamientos, libertad de circulación y personal, prohibición de reuniones y actividades y otras restricciones de derechos por la pandemia del Coronavirus." Diario La Ley, núm. 9608, de 6 de abril de 2020. Editorial Wolters Kluwer, p.1.

58 COTINO HUESO, L., "EI TC, las manifestaciones y la constitucionalidad del confinamiento." https://blogs.elconfidencial.com/espana/tribuna/2020-05-04/tc-manifestaciones-linea-favorableconstitucionalidad-confinamiento_2577544/

${ }^{59}$ Ibídem.

${ }^{60}$ COTINO HUESO, L., "Las restricciones del derecho de reunión y manifestación bajo el Covid 19 (y la aparente constitucionalidad del decreto de alarma 463/2020 para el Tribunal Constitucional)", en RODRÍGUEZ AYUSO J. F., y ATIENZA, E., (eds.), Retos jurídico-éticos ante la crisis del Covid-19: perspectiva interdisciplinar, Wolters Kluwer, Madrid, 2020. Edición: 


\section{Las limitaciones sobre el derecho de huelga}

\section{A) Planteamiento}

Centrándose en la temporalidad de las normas dictadas para combatir la enfermedad del coronavirus, hay que tener presente, según Cordero González, que estas normas tienen "una triple provisionalidad": Ia relativa a "la crisis sanitaria"; la conectada a "la gestión y aplicación de las soluciones normativas", y la ocasionada por "las reacciones de los grupos de opinión" perjudicados por estas decisiones ${ }^{61}$.

En otro estudio anticipa el laboralista Cordero González que, en nuestro país, "la inestabilidad política será un lastre", por lo que sería eficaz cambiar la legislación orgánica, es más, sería útil que se produjese un cambio constitucional con el fin de modificar el artículo $116 \mathrm{CE}$. Asevera que tendremos que indagar recursos "públicos", ya que la fragilidad de determinados grupos, como el de nuestros mayores, "inhabilita las redes de seguridad ordinarias." Estas actuaciones deben ir unidas a determinadas predicciones complementarias, que se adelanten a la innovadora "necesidad" del trabajo a distancia durante esta crisis sanitaria. Además, insiste en la relevancia que supone el diálogo y la concertación social. Incluso anticipa la posibilidad de aplicar un "ingreso mínimo vital" ${ }^{\text {, }}$, que posteriormente se ha aprobado $^{63}$.

Desde un prisma constitucional Carrillo tiene en cuenta (y no es el único que opina así) que, cuando en el pasado mes de marzo se aprobó el Decreto 463/2020 decretando el estado de alarma, la postura gubernamental resultó ser acertada $^{64}$. Sea como sea, las medidas "de confinamiento y otras gravemente

septiembre 2020. Núm. de páginas: 676. ISBN: 978-84-18349-12-6. ISBN Digital: 978-8418349-13-3. Colección: LA LEY, pp. 29-53.

${ }^{61}$ CORDERO GONZÁLEZ, J., "Estado de alarma por la COVID-19 y su impacto en el marco normativo laboral español", Trabajo y Derecho, núm. 65 (mayo 2020). 10 p. Obtenido de la URL https://www.smarteca.es/my-library/issues/SMT2015106 (visitada el 4 de julio de 2020).

62 CORDERO GONZÁLEZ, J., "Derechodemia laboral y COVID-19: diques de contención ¿provisionales? frente a un desbordamiento oceánico", Trabajo y Derecho, núm. 66 (jun. 2020). 30 p. Obtenido de la URL https://www.smarteca.es/my-library/issues/SMT2015106 (visitada el 4 de julio de 2020), pp. 23-24.

${ }^{63}$ RDL 20/2020, de 29 de mayo, BOE núm. 154, de 1 de junio de 2020.

${ }^{64}$ CARRILLO, M., "Los derechos en tiempo de pandemia." Publicado en el Blog «Al Revés y al Derecho» el 17/05/2020. https://www.acoes.es/blog/2020/05/17/los-derechos-en-tiempo-depandemia/ 
restrictivas" entendió Cotino Hueso que se pueden llevar a cabo en base a la normativa común, por lo que resulta contradictorio que el vigente ordenamiento ordinario, aplicable a circunstancias extraordinarias, autorice a imponer limitaciones que, a priori, no se podrían aplicar ni con el estado de alarma, ya que conllevan una auténtica suspensión de algunos derechos ${ }^{65}$.

\section{B) El derecho de huelga en circunstancias ordinarias}

Como ya hemos planteado, la normativa interna que concreta y despliega la huelga es muy diversa y está dispersa por nuestro ordenamiento jurídico ${ }^{66}$. Si ordenamos cronológicamente dicha normativa empezamos por el Real Decreto Ley 17/1977, de relaciones de trabajo, que es una norma preconstitucional, cuyo Preámbulo y Título I, están dedicados a la huelga, tras recibir el visto bueno de la STC 11/1981, de 8 de abril, que, no obstante, declaró inconstitucionales nada menos que 19 de los 45 artículos iniciales. En su Preámbulo hace alusión a novedades muy relevantes, que ponen de relieve que esta medida de presión social ha pasado de estar tipificada penalmente (por ejemplo, durante el franquismo), a poder ejercerse libremente. Por ello, se produce el relevo de las disposiciones jurídicas en vigor por otras nuevas donde queda sacralizada la huelga como una facultad. Todos estos cambios que afectan a la huelga, conducen a que se regule de forma independiente el

65 COTINO HUESO, L., "Los derechos fundamentales en tiempos del Coronavirus. Régimen general y garantías y especial atención a las restricciones de excepcionalidad ordinaria.", op. cit., p. 89.

66 A nivel internacional, el derecho de huelga no se prevé ni en la Declaración Universal de Derechos Humanos de las Naciones Unidas, de 10 de diciembre de 1948, ni en el Pacto Internacional de Derechos Civiles y Políticos, de 19 de diciembre de 1966, ni en el Convenio Europeo de Derechos Humanos, de 4 de noviembre de 1950.

Por el contrario, sí se recoge en el art. 8.1.d del Pacto Internacional de Derechos Sociales, Económicos y Culturales, de 19 de diciembre de 1966: "Los Estados Partes en el presente Pacto se comprometen a garantizar: d) El derecho de huelga, ejercido de conformidad con las leyes de cada país". También se contempla en el art. 6.4 de la Carta Social Europea, hecha en Turín el 18 de octubre de 1961. Instrumento de Ratificación de 29 de abril de 1980. El contenido de dicho artículo es el siguiente: "Para garantizar el ejercicio efectivo del derecho de negociación colectiva, las Partes Contratantes se comprometen. Y reconocen: 4. El derecho de los trabajadores y empleadores, en caso de conflicto de intereses, a emprender acciones colectivas, incluido el derecho de huelga, sin perjuicio de las obligaciones que puedan dimanar de los Convenios Colectivos en vigor." Además, se regula en el art. 28 de la Carta de Derechos Fundamentales de la Unión Europea de 2007: "Los trabajadores y los empresarios, o sus organizaciones respectivas, de conformidad con el Derecho de la Unión y con las legislaciones y prácticas nacionales, tienen derecho a negociar y celebrar convenios colectivos, en los niveles adecuados, y a emprender, en caso de conflicto de intereses, acciones colectivas para la defensa de sus intereses, incluida la huelga". 
arbitraje estatal en los conflictos colectivos de trabajo, que precisa conservarse si los afectados optan por emplear este mecanismo de reparación ${ }^{67}$.

Más concretamente, se declaran "nulos" aquellos convenios laborales previstos en "contratos individuales" que incluyan limitar o renunciar al ejercicio de la huelga. Proclamar este derecho, independientemente de su campo de actuación, precisa siempre que se llegue a un pacto explícito sobre el mismo. De cualquier modo, están legitimados para pactar la declaración de huelga indirectamente los operarios, mediante las personas que los representen, y, de forma directa, los mismos asalariados del lugar de trabajo, implicados por la disputa. El pacto alcanzado para llevar a cabo la huelga se dará a conocer al empleador del negocio implicado y al responsable en materia "laboral" por intermediarios de los asalariados. Dicha notificación incluirá su finalidad, actuaciones llevadas a cabo para solucionar los desacuerdos, día y hora de su comienzo y quiénes forman el "comité de huelga". Cuando la huelga involucre a negocios que tengan como cometido cualquier tipo de "servicios públicos", el plazo para preavisar al empleador o empleadores del negocio y al responsable en materia "laboral" será como mínimo de "diez días", es decir, se amplía cinco días más en este tipo de empresas. Quienes actúen en nombre de los trabajadores, previamente al arranque de la huelga, tendrán que difundirla, para que se informe a las personas que usen dicho servicio público ${ }^{68}$.

El ejercicio de la huelga no produce la extinción de la relación laboral, ni ocasiona ninguna multa o castigo, a no ser que el asalariado, mientras dure la misma, cometiese una "falta laboral". Declarada la huelga se interrumpe el contrato laboral y el empleado no percibirá dinero ni ayuda alguna "por desempleo, ni a la económica por incapacidad laboral transitoria." El asalariado huelguista permanece en situación de "alta especial en la Seguridad Social", con interrupción del deber de cotizar, tanto por el empleador como por el mismo empleado. Tampoco le corresponde al empleador relevar a los trabajadores en huelga por otros no ligados a su negocio, excepto el supuesto de no cumplir con los deberes previstos en este precepto ${ }^{69}$.

${ }^{67}$ RDL 17/1977 de 4 de marzo, sobre relaciones de trabajo, Preámbulo. «BOE» núm. 58, de 9 de marzo de 1977.

${ }^{68}$ Ibídem, arts. 2, 3 y 4. La STC 11/1981 declara inconstitucional que lo establecido en este precepto se lleve a cabo "en cada centro de trabajo".

69 Ibídem, art. 6. Apartado 7. de este precepto declarado inconstitucional por STC 11/1981, de 8 de abril, "en cuanto atribuye de manera exclusiva al empresario la facultad de designar los trabajadores que durante la huelga deban velar por el mantenimiento de los locales, maquinaria e instalaciones". 
A partir del instante del "preaviso" y en tanto se ejercite la huelga, todos los actores implicados deberán dialogar para alcanzar un pacto ${ }^{70}$. Una huelga podrá ser "ilegal": 1) por causas políticas o con otro motivo diferente al puramente laboral de los empleados perjudicados; 2) por "solidaridad o apoyo", excepto si concierne de forma directa a causas laborales de los que la fomentan o mantienen.; 3) si tiene por finalidad modificar, mientras se esté llevando a cabo, lo acordado en un laudo o en un convenio colectivo; 4) si contraria lo establecido en el RDL 17/1977, o lo explícitamente acordado en convenio colectivo para satisfacer las disputas ${ }^{71}$.

Una de las restricciones del derecho de huelga son los servicios esenciales de la comunidad, previstos en el art. 28.2 CE, que, según Cámara Villar, son "un concepto jurídico indeterminado, que debe concretarse legal 0 jurisprudencialmente"72. Precisamente, la STC 26/1981 concibe los servicios esenciales como "actividades industriales o mercantiles de las que derivan prestaciones vitales o necesarias para la vida de la comunidad. [...] Para que el servicio sea esencial deben ser esenciales los bienes e intereses satisfechos. Como bienes e intereses esenciales hay que considerar los derechos fundamentales, las libertades públicas y los bienes constitucionales protegidos"73.

En relación a los servicios esenciales Montoya melgar plantea en este RDL "una perturbadora 'dualidad jurisdiccional'" que ocasiona cuestiones complejas, "así, se ha planteado qué suerte corre la sanción impuesta a un huelguista que incumple los servicios mínimos, cuando posteriormente la resolución administrativista que implantó esos servicios esenciales es declarada nula por la jurisdicción contencioso-administrativa"74. En otras palabras, como razona Cámara Villar, "los servicios mínimos y los servicios esenciales se pueden recurrir de forma distinta ante la jurisdicción contenciosa y ante la jurisdicción social. Y estas dos vías, contenciosa y laboral, no son excluyentes porque ello

\footnotetext{
${ }^{70}$ Ibídem, art. 8.

${ }^{71}$ Ibídem, art. 11. Se declara la inconstitucionalidad del apartado b) por STC 11/1981.

72 CÁMARA VILLAR, G., "Capítulo XXII: Constitución Económica y Derechos Sociales", op. cit., p. 356.

${ }^{73}$ STC 26/1981, de 17 de julio, F.J. 9. BOE núm. 193, de 13 de agosto de 1981.

${ }^{74}$ MONTOYA MELGAR, A., "Los límites del derecho de huelga presente y futuro", A. ARIAS DOMÍNGUEZ (coord.) Cuestiones laborales de actualidad: Estudios jurídicos en homenaje al profesor Feliciano González, 2013, pp. 48-49.
} 
depende del motivo del recurso e, incluso, de cuál sea el momento en que este se formaliza" ${ }^{\text {"75 }}$.

Las funciones establecidas para el comité de huelga, según este RDL 17/1977, son salvaguardar que se cumplan las prestaciones imprescindibles para proteger a seres humanos y a bienes, y para la conservación de bienes, máquinas, etc. necesarios para reanudar la actividad laboral (más conocidos como servicios de mantenimiento).

En este ámbito, hace diez años expuso Martínez Abascal que, en el campo de los vínculos de trabajo, una de las labores jurídicas aplazadas desde el cambio democrático español radicaba en afrontar una regulación mediante ley orgánica del derecho de huelga que "clarifique, corrija y ponga al día una normativa dispersa, asistemática e insuficiente, que no da cumplida cuenta del potencial transformador que la Constitución (CE) condensa en el art. 28.2"76.

Existen alusiones a la huelga también en la Ley Orgánica 6/1985, del Poder Judicial, que dispone que uno de los derechos colectivos de los que disponen los funcionarios públicos es el derecho de huelga, salvaguardando la conservación de "los servicios esenciales de la Administración de Justicia", y estima como "faltas muy graves": el incumplimiento de la obligación de atender dichas prestaciones "esenciales" si se declara una huelga ${ }^{77}$.

Centrándonos ya en la Ley Orgánica de Libertad Sindical de 1986, esta expone que las centrales sindicales, para desempeñar su libertad sindical, tienen derecho a desempeñar su actuación sindical "en la empresa o fuera de ella, que comprenderá, en todo caso, el derecho a la negociación colectiva, al ejercicio del derecho de huelga, al planteamiento de conflictos individuales y colectivos" $^{\prime 78}$.

Por lo que atañe a la Ley 36/2011, reguladora de la jurisdicción social, establece que todo empleado u organización sindical que, alegando "un

${ }^{75}$ CÁMARA VILLAR, G., "Capítulo XXII: Constitución Económica y Derechos Sociales", BALAGUER CALLEJÓN , F., (coord.) Manual de Derecho Constitucional. Madrid, Tecnos, vol. II., pp. 356-357.

${ }^{76}$ MARTÍNEZ ABASCAL, V. A., "La titularidad del derecho de huelga los sujetos titulares en el plano individual y en el plano colectivo". Revista del Instituto de Estudios Económicos, núms. 23, 2010 (Ejemplar dedicado a: La regulación del derecho de huelga en España), pp. 27-28.

${ }_{77}$ Arts. 468 bis 1. p, y 536. 15 (faltas muy graves) y art. 496. d (derechos de los funcionarios públicos) de la Ley Orgánica 6/1985, de 1 de julio, del Poder Judicial «BOE» núm. 157, de 02 de julio de 1985.

${ }_{78}$ Art. 2.2.d. de la Ley Orgánica 11/1985, de 2 de agosto, de Libertad Sindical. «BOE» núm. 189, de 8 de agosto de 1985. 
derecho o interés legítimo", estime perjudicados "los derechos de libertad sindical, huelga", podrá solicitar su amparo a través del procedimiento establecido en la jurisdicción social. Por otra parte, los laudos que finalicen con una "huelga" o con "conflictos colectivos" se homologan a las resoluciones judiciales firmes, para ser ejecutados definitivamente ${ }^{79}$.

Se reconoce el derecho de huelga para los trabajadores en el Real Decreto Legislativo 2/2015, y para ejercitar este derecho puede ser suspendido un contrato de trabajo. A lo largo de los acuerdos para actualizar "un convenio colectivo", si no existe acuerdo, se considerará vigente, aunque los pactos por los que "se hubiera renunciado a la huelga durante la vigencia de un convenio decaerán a partir de su denuncia" 80 .

\section{C) Estado de alarma de 2020 y su incidencia sobre el derecho de huelga}

Uno de los asuntos más debatidos y anhelados, cuando se trata del derecho fundamental de huelga (art. 28.2 de la CE), consiste en hallar el momento social, político y sindical oportuno para que este derecho se desarrolle por Ley Orgánica. En este sentido, en 2010 Palomeque López promovía que esta regulación jurídica fuese fruto del "diálogo social" y que reemplazase al "ya desgastado cuerpo normativo que ha dado todo su juego a lo largo de treinta años, acometiéndose, así, un desarrollo oportuno y moderno" del citado precepto constitucional ${ }^{81}$.

En esta futura y ansiada Ley Orgánica de Huelga hay quien considera que su ejercicio ha de salvaguardar "los intereses y derechos de la comunidad e incluso de la empresa" sin que se convierta en "ineficaz la defensa de los intereses de los trabajadores". Tengamos en cuenta además que los obstáculos al mencionado derecho constitucional "no son sólo los derivados de su acomodación a otros derechos fundamentales, sino a otros bienes

\footnotetext{
${ }^{79}$ Arts. 2, 3, 177.1 y 68 respectivamente de la Ley 36/2011, de 10 de octubre, reguladora de la jurisdicción social. «BOE» núm. 245, de 11 de octubre de 2011.

${ }^{80}$ Arts. 4.1, 45.1.1 y. 86. 3 del Real Decreto Legislativo 2/2015, de 23 de octubre, por el que se aprueba el texto refundido de la Ley del Estatuto de los Trabajadores. «BOE» núm. 255, de 24 de octubre de 2015.

${ }^{81}$ PALOMEQUE LÓPEZ, M. C., "La regulación de la huelga y sus inconvenientes funcionales". Revista del Instituto de Estudios Económicos, núms. 2-3, 2010 (Ejemplar dedicado a: La regulación del derecho de huelga en España), p. 87.
} 
constitucionalmente protegidos", como "el derecho a la salud y protección social de los ciudadanos"82.

En circunstancias ordinarias, derechos tan limitados como el que nos ocupa son escasos. González Ortega constata esto "en el uso decreciente de la huelga, prácticamente reservada a los casos en los que tiene un fuerte impacto mediático, haciéndola visible y con ello el conflicto que está en su base, a las situaciones en que quedan afectados los múltiples usuarios de los servicios públicos o en las que las estructuras productivas u organizativas de la empresa hacen que sus efectos dañosos sobre sus intereses económicos sean más significativos". De ahí que califique al derecho de huelga de forma muy gráfica como "un derecho acorralado"83.

Efectivamente, el estudio de las restricciones a este derecho está omnipresente en la doctrina, especialmente la laboralista. Sin ánimo de ser exhaustivos, entre los estudios realizados antes de 2020, destacamos el llevado a cabo por Martín Valverde en 1986, centrado en los límites de este derecho fundamental en los funcionarios públicos ${ }^{84}$. Actualmente, el ejercicio de la huelga por parte de los empleados públicos se contempla en el Real Decreto Legislativo 5/2015, que asegura que estos trabajadores disfrutan colectivamente de una serie de derechos individuales, entre ellos el de huelga. Estos mismos asalariados públicos cuando lleven a cabo una huelga, no recibirán la remuneración adecuada al espacio de tiempo que hayan estado de huelga. $Y$, entre las faltas disciplinarias muy graves, sobresale el llevar a cabo conductas dirigidas a condicionar "el libre ejercicio" de este derecho, e incumplir el deber de prestar "los servicios esenciales" en el supuesto de huelga ${ }^{85}$.

Totalmente limitado permanece este derecho para los miembros de las Fuerzas y Cuerpos de Seguridad del Estado, a tenor de lo establecido en su Ley Orgánica, que prohíbe la huelga realizada en pro de "los intereses preeminentes que corresponde proteger a los Cuerpos de Seguridad, al objeto

82 PORRET GILABERT, M., "El derecho de huelga y sus límites legales", Revista Técnico Laboral, vol. 30, no 117, 2008, p. 25.

${ }^{83}$ GONZÁLEZ ORTEGA, S., "El derecho de huelga: un derecho fundamental acorralado". Lección Inaugural del Curso Académico 2017/2018. Universidad Pablo de Olavide. Septiembre, 2017, pp. 3, 52 y 53.

${ }^{84}$ MARTÍN VALVERDE, A., "Los límites del derecho de huelga en la Administración Pública". Revista española de derecho constitucional, ISSN 0211-5743, Año 6, núm. 18, 1986, p. 50.

${ }^{85}$ Arts. 15, 30.2 y 95.2 del Real Decreto Legislativo 5/2015, de 30 de octubre, por el que se aprueba el texto refundido de la Ley del Estatuto Básico del Empleado Público. «BOE» núm. 261, de 31 de octubre de 2015. 
de asegurar la prestación continuada de sus servicios, que no admite interrupción". Más concretamente, los componentes de este colectivo no podrán realizar nunca este derecho, "ni acciones sustitutivas del mismo o concertadas" con el objetivo de perturbar "el normal funcionamiento de los servicios" ${ }^{86}$. Igual ocurre con los componentes del Ejército pues no podrán acudir ni a la huelga, ni a la negociación colectiva, ni a actuaciones que tengan que ver con el conflicto colectivo ${ }^{87}$.

En 1992, un año tan emblemático para nuestro país, cultural y deportivamente hablando, Iglesias Cabero concibe este derecho como "un fenómeno de alguna manera paradógico [sic], en cuanto permite a una de las partes contratantes incumplir, aunque sea temporalmente, las obligaciones que dimanan del contrato de trabajo, sin posibilidad de que la otra parte resuelva la relación laboral por esta sola causa"88.

Más concretamente, relacionado con los servicios esenciales sobresale la doctrina del Comité de Libertad Sindical de la Organización Internacional del Trabajo (OIT), que nos aporta ciertos datos determinantes respecto a la índole extraordinaria de estas decisiones "tan drásticas, incluso excesivas, de intervención", que examinamos: a) "un servicio no esencial puede convertirse en servicio esencial cuando la duración de una huelga rebasa cierto período o cierto alcance y pone así en peligro la vida, la seguridad de la persona o la salud de toda o parte de la población", b) el criterio por el cual "el control del tráfico aéreo puede considerarse como un servicio esencial se aplica a todas las huelgas, [...] dado que estas pueden ser tan peligrosas como una huelga tradicional para la vida, la seguridad personal o la salud de la totalidad o parte de la población"”89.

${ }^{86}$ Apartado II del Preámbulo y art. 6.8 de la Ley Orgánica 2/1986, de Fuerzas y Cuerpos de Seguridad del Estado, de 13 de marzo. «BOE» núm. 63, de 14 de marzo de 1986.

87 Arts. 7.2 y 42 de la LO 9/2011, de 27 de julio, de derechos y deberes de las Fuerzas Armadas. «BOE» núm. 180, de 28 de julio de 2011.

${ }^{88}$ IGLESIAS CABERO, M., "Algunos límites del derecho de huelga". Dirección y organización: Revista de dirección, organización y administración de empresas, ISSN 1132-175X, núm. 2, 1992, p. 20.

${ }^{89}$ https://www.ilo.org/dyn/normlex/es/f?p=NORMLEXPUB:70002:0::NO::P70002_HIER_ELEME

NT_ID,P70002_HIERLEVEL:3945742,3 OIT. Recopilación de Decisiones del Comité de Libertad Sindical: "Casos en que la huelga puede ser objeto de restricciones o incluso de prohibición y garantías compensatorias".

Esta información se recoge en $M^{a}$. D. MARTÍNEZ CUEVAS, "El estado de alarma y el derecho fundamental de huelga: el caso de los controladores civiles de tráfico aéreo en España”, op. cit., pp. 11-12. 
Teniendo en cuenta, como hemos manifestado anteriormente, que el estado de alarma no suspende el ejercicio del derecho de huelga, especifica A. Baylos que este derecho "permanece inalterado, y esta medida de presión puede por consiguiente ser utilizada por los sindicatos, los representantes electivos en la empresa y los propios trabajadores sin restricción legal alguna derivada de esta situación de excepción. Una conclusión que afecta fundamentalmente a los sectores industriales y de la construcción”. En cualquier caso, decretado el estado de alarma, se deben preservar los instrumentos de protección previstos para la práctica del derecho de huelga en los mencionados "sectores esenciales"90.

En situaciones anómalas y excepcionales, como las que estamos viviendo, para Ituren y Esteve es suficiente con "imaginar si comenzase a faltar abastecimiento alimentario o de primera necesidad. En definitiva, es un hecho que la paralización de la actividad laboral consecuencia de una huelga es uno de los derechos cuya limitación puede verse afectada más rápidamente atendiendo a que el trabajo es uno de los elementos centrales para remediar estos episodios"91.

En otro orden de consideraciones, las nuevas tecnologías de la comunicación y de la información repercuten, sin duda, en el disfrute y práctica del derecho de huelga. Entrando en detalle, básicamente estas tecnologías inciden en tres aspectos, a juicio de Valle Muñoz: "a) la videovigilancia empresarial de los piquetes informativos durante una huelga"; b) el "esquirolaje tecnológico"; y c) el "teletrabajo", en este supuesto es preciso replantearse tácticas gremiales, encaminadas a lograr que, aquellos equipamientos técnicos que la compañía deja a sus trabajadores para llevar a cabo sus funciones, incluida la utilización de plataformas digitales, puedan también posibilitarles el justificado disfrute del derecho de huelga ${ }^{92}$.

Evidentemente, una novedad la representa el RDL 28/2020, sobre el trabajo a distancia, concebido como "trabajo" que se presta fuera de los establecimientos

90 BAYLOS GRAU, A., “¿Se puede convocar una huelga durante el estado de alarma?" https://www.nuevatribuna.es/articulo/actualidad/trabajo-laboral-coronavirus-huelgaestadodealarma/20200326165602172689.html

${ }^{91}$ ESTEVE SEGARRA, A., y ITUREN OLIVER, A., "El derecho de huelga en tiempos del estado de alarma por el COVID-19", Trabajo y Derecho, núm. 65 (mayo 2020), Editorial Wolters Kluwer, p. 6 .

${ }^{92}$ VALLE MUÑOZ, F. A., "La incidencia de las nuevas tecnologías en el ejercicio del derecho de huelga". Revista Aranzadi de Derecho y Nuevas Tecnologías, 2020, núm. 52 (Enero-Abril), pp. 22 y 23. 
y centros habituales de la empresa y del que el teletrabajo es una subespecie que conlleva que se realicen servicios con innovadoras técnicas. Es más, en la citada norma se especifica que el diálogo o concertación colectiva podrá fijar los requisitos para salvaguardar la práctica de "los derechos colectivos de las personas trabajadoras a distancia, en atención a las singularidades de su prestación, con respeto pleno al principio de igualdad de trato y de oportunidades entre la persona trabajadora a distancia y la que desempeñe tareas en el establecimiento de la empresa"93.

\section{ALGUNAS PROPUESTAS DE LEGE FERENDA Y DE CONSTITUCIÓN FERENDA}

\section{Balance de lege ferenda a partir del estado de alarma de 2010 y su incidencia sobre el derecho de huelga}

Traemos aquí a colación las conclusiones a las que llegué en abril de $2020^{94}$, y que transcribimos a continuación:

Se trató de "una huelga ilegal al no haberse realizado conforme al procedimiento judicialmente previsto en la Ley 36/2011, de 10 de octubre, reguladora de la Jurisdicción Social, lo que comporta que transcurra mucho tiempo, durante el cual, si los huelguistas no los respetan pueden causarse daños irreparables a otros derechos fundamentales. Al tratarse de una huelga salvaje, al margen de los límites y requisitos legales, es lícito preguntarse ¿qué otra opción le queda al poder público para garantizar esos derechos fundamentales? ¿hicieron lo correcto declarando el estado de alarma o cabía otra opción como declarar el estado de excepción?”.

Por otra parte, "la cuantía pactada al colectivo de controladores aéreos por esas horas se negoció en un acuerdo extraestatutario, lo que significa que no

${ }^{93}$ Exposición de Motivos del art. 19 del Real Decreto-ley 28/2020, de 22 de septiembre, de trabajo a distancia. «BOE» núm. 253, de 23 de septiembre de 2020. Este Real Decreto-ley modifica diversas normas jurídicas: la Ley $36 / 2011$, de 10 de octubre, reguladora de la jurisdicción social; la Ley del Estatuto de los Trabajadores aprobado por el Real Decreto Legislativo 2/2015, de 23 de octubre; el Real Decreto-ley 20/2020, de 29 de mayo, por el que se establece el ingreso mínimo vital.

${ }_{94}$ Todas estas conclusiones están recogidas en MARTíNEZ CUEVAS, Ma․ D., "El estado de alarma y el derecho fundamental de huelga: el caso de los controladores civiles de tráfico aéreo en España", op cit., pp. 15-16. 
tiene ni valor normativo ni eficacia general, solo inter partes y, además, por lo que vemos, el número de horas es tan elevado (1.670 horas anuales, sin perjuicio de la posibilidad de ser incrementada con horas extraordinarias hasta un máximo de 80 horas al año) que excede los límites admitidos por el ordenamiento laboral, con lo cual podría ser entendido como un pacto ilícito".

Algo que no podemos olvidar es que "los controladores aeroportuarios es un gremio privilegiado por sus emolumentos anuales y pese a todo descontento con sus condiciones laborales (horario laboral y horas extraordinarias básicamente), ello no impide que puedan considerarse legítimas sus aspiraciones desde la perspectiva sustancial, pero desde el momento en que no cumple con el procedimiento legalmente previsto su huelga se convierte en ilegal y todo cambia. Por tanto, en nuestra opinión, ante la paralización de un servicio esencial como es el del transporte aéreo provocado por la cesación de sus funciones por parte de los controladores civiles, el Gobierno no debería de haber declarado el estado de alarma (ya que no se cumplía más que uno de los motivos para poder declararlo)".

Es más, frente a un tipo de huelga como la acaecida en 2010, "encubierta, salvaje e ilegal (lo que es más grave) en un servicio esencial para la comunidad como es el servicio aeroportuario por parte de un colectivo como el de los controladores civiles aéreos que reivindicaba, en plena crisis económica y financiera del país, y en unas fechas de mucha afluencia turística tanto de nacionales como de extranjeros, el Gobierno tenía que reaccionar de forma urgente y extraordinaria pero no del modo en que lo hizo declarando el estado de alarma".

Aunque no nos llevemos a engaño, porque si el Gobierno en el puente festivo de la Constitución de 2010 hubiese afrontado "este grave problema mediante la declaración del estado de excepción, indudablemente había suficientes motivos para proclamarlo, a tenor del art. 13 de la LO 4/81, aunque ello habría conllevado consecuencias más graves y trascendentales para el colectivo de los controladores de tránsito aéreo, especialmente porque durante el estado de excepción se pueden suspender algunos derechos fundamentales como el de huelga". 
Sea como sea, pese a que la huelga realizada por los controladores civiles de tránsito aéreo "hubiese sido legal, ni material ni procedimentalmente el Gobierno tampoco habría estado legitimado para declarar el estado de alarma, ya que bajo su vigencia no se puede suspender ningún derecho fundamental, como el de huelga. Cuando una huelga es legal tiene un plus de protección o tutela constitucional máxima, por el contrario, cuando deviene ilegal (salvaje) la solución que nos ofrece el ordenamiento jurídico-laboral es que ese tipo de huelga no goza de esa tutela máxima".

Por ende, inferimos que "fue de todo punto ilegal la aprobación del RD 1673/2010, de 4 de diciembre, por el que se declara el estado de alarma para la normalización del servicio público esencial del transporte aéreo y el RD 1717/2010, de 17 de diciembre, por el que se prorroga el estado de alarma, al no cumplirse más que uno de los requisitos exigidos por el art. 4 LO 4/1981. En realidad, insistimos, sólo concurría una de las dos causas previstas para declarar el estado de alarma: 'paralización de servicios esenciales para la comunidad'".

En consonancia con todo lo expuesto una de las proposiciones "de lege ferenda que realizamos es la supresión de la coletilla final en el art. 4, letra b) de la LO 4/1981, ("y concurra alguna de las demás circunstancias o situaciones contenidas en este artículo") para que no vuelva a ocurrir un supuesto como el ocurrido en nuestro país en diciembre de 2010. Una propuesta de Constitución ferenda es reformar el art. 55.1 CE si se quiere que, de ahora en adelante, el estado de alarma implique la suspensión de algún derecho fundamental como es el de huelga (28.2 CE)".

Centrándonos en el RDL 17/1977, de 4 de marzo, sobre relaciones de trabajo, sería "lógico y natural plantearse como una de las hipotéticas conclusiones de esta investigación hacer una propuesta de lege ferenda para que se derogase el mencionado RDL, al menos en lo que respecta al derecho de huelga regulado restrictivamente". No obstante, los laboralistas estiman que "esta hipotética Ley Orgánica de desarrollo del art. 28. 2 CE sería una norma jurídica que refundiese toda la doctrina del Tribunal Constitucional, y aún siendo ello totalmente deseable, ahora mismo no es el momento más oportuno, ya que no hay consenso político, e incluso iría más allá, en el marco del diálogo social”, 
en relación a la esencialidad de los servicios prestados (tanto las restricciones a su ejercicio como su ordenación).

\section{Lecciones de lege ferenda del estado de alarma de 2020 y sus limitaciones sobre el derecho de huelga}

Durante el vigente estado de alarma los artículos 55.1 y 116 de la Constitución no permiten, en sentido estricto, la suspensión (interrupción temporal) de ningún derecho, sólo el recorte de los mismos. A diferencia de otros derechos fundamentales que se han restringido durante el estado de alarma, como la libertad de circulación, el derecho de reunión, el derecho de manifestación, la libertad de culto o el derecho a la protección de datos, etc... el derecho de huelga no se ha podido recortar en esta época. Primero, y ante todo, porque no es un derecho que se pueda ni restringir, ni mucho menos suspender, durante el estado de alarma. Y segundo, por la situación y circunstancias que aún estamos atravesando, dado que las personas (durante y después del confinamiento), estaban encerradas en sus casas teletrabajando, mientras que otras personas estaban sometidas a ERTEs y a EREs, con lo cual no ha podido haber concertación previa en el lugar de trabajo para preparar una huelga en defensa de sus intereses profesionales y laborales. Además, la sociedad española, al menos en los primeros estadios de esta enfermedad, estaba más preocupada por su salud y por el contagio de este virus y sus consecuencias (cuarentena, ingreso en el hospital, efectos secundarios) que por mejorar sus condiciones laborales.

En nuestra opinión, durante la pandemia se ha producido un uso excesivo de los Reales Decretos Leyes por parte del Gobierno. En este sentido, echamos de menos un mayor control del Congreso hacia la actuación del Ejecutivo (habría que reformar la CE y el Reglamento del Congreso y del Senado, así como de la LOEAES). En este terreno, se ha puesto de relieve el gran protagonismo del Congreso sobre el Senado en materia de prórrogas del estado de alarma. Proponemos una reforma de la Constitución en la que se empodere al Senado, como Segunda Cámara, sí, pero como una Cámara que representa los intereses territoriales, ya que al tener un Estado autonómico las 17 CCAA tienen mucho que decir en sus respectivos territorios.

Echamos en falta mayor unión y cohesión política entre mayoría y minoría parlamentaria, quizás habría que reformar la CE y el Reglamento del Congreso 
y del Senado para que en una futura catástrofe sanitaria o de otro tipo, de graves dimensiones, como la que se vive en nuestro país ( $\mathrm{y}$ a nivel mundial) hubiese mayor acercamiento entre la mayoría y la oposición parlamentaria en pro del bienestar y del interés general de la sociedad española.

Entendemos que ha existido un correcto uso del RD que decreta el estado de alarma. Demasiada improvisación es criticable, pero también es entendible por la anomalía y el carácter inusual (extraordinario y excepcional) de la pandemia. Por ello, esta crisis sanitaria y económica nos debería servir también para que se prevea la existencia de una partida de dinero, en los Presupuestos Generales del Estado, reservada para comprar material sanitario en futuras crisis epidemiológicas, así como una partida de dinero reservada a investigación sanitaria, especialmente en centros de investigación y universidades españolas. Y por supuesto, sería encomiable que existiese una partida de dinero reservada para que se proporcionen mayores ayudas, tanto a los trabajadores por cuenta ajena como a los autónomos en las Pequeñas y Medianas Empresas (PYMES), en especial a las empresas dedicadas al comercio, al sector turístico, de restauración y de ocio, entre otras empresas afectadas, y que son tan importantes para nuestro país.

A diferencia de lo que opinaba en el primer trimestre de 2020, ahora disiento y considero que sí es el momento de redactar una ley orgánica postconstitucional de acuerdo con los nuevos tiempos y en línea con lo que algunos laboralistas han comentado desde hace tiempo: que se pueda suspender la huelga durante una pandemia si afecta a los servicios públicos esenciales (sanidad, transportes públicos, etc.). Insistir, por tanto, en derogar el RDL 17/1977 y regular la huelga como se merece este país (desarrollo mediante Ley Orgánica del art. 28.2 CE), y que sea fruto del consenso político y sindical, acorde con nuestro sistema jurídico-constitucional, basándose pues en principios y valores propios de nuestro Estado social y democrático de Derecho. Y siguiendo, claro está, la jurisprudencia constitucional en la materia. En suma, se trataría de una Ley Orgánica democrática, conciliadora, con visos de permanencia en el tiempo, consensuada por todos los sectores implicados, que no haga tanto hincapié en los límites de este derecho constitucional y que se convierta en un instrumento útil, eficaz y justo en las relaciones laborales.

Aunque una futura Ley de huelga debiera permitir que se suspendiese en un estado de alarma el derecho de huelga, siempre que se perjudicasen claramente los servicios esenciales o el abastecimiento de productos de 
primera necesidad mediante el ejercicio de esta medida de presión colectiva. En este sentido, estoy planteando una reforma con mayor calado, una reforma constitucional del art. 55 de nuestra Constitución.

Es más, en línea con lo que opinan destacados laboralistas, sería urgente que en esta futura Ley Orgánica se ofreciese un concepto de servicios esenciales y de servicios mínimos para evitar lo que se ha dado en llamar "la perturbadora dualidad jurisdiccional"95 en este terreno, como hemos tenido ocasión de exponer con anterioridad.

Siendo muy optimistas, frente a los indudables perjuicios sanitarios, económicos y laborales de esta pandemia, podemos contraponer ciertas ventajas, como la toma de conciencia previa sobre la importancia de invertir más en salud y en investigación sanitaria. Incluso, existe una percepción más positiva y respetuosa hacia nuestro personal sanitario y hacia los miembros de las Fuerzas y Cuerpos de Seguridad del Estado, como todos hemos podido comprobar a lo largo de estos meses de confinamiento domiciliario. Es más, ante las consecuencias económicas de amplias capas de la población, los ejemplos de solidaridad se han incrementado notablemente. Asimismo, esta pandemia sanitaria ha conducido al denominado teletrabajo o trabajo desde casa, convirtiéndose esta práctica en algo ya normalizado desde marzo de $2020^{96}$ que, si no ha aparecido para quedarse totalmente a tiempo completo en nuestras vidas, quizás sí para permanecer a tiempo parcial en las mismas. Y en base a ello, opinamos que se ha podido conciliar mejor la vida personal, familiar y laboral, y como consecuencia de ello hay menos estrés.

Este trabajo en su conjunto pone de manifiesto el eterno dilema en el binomio: seguridad y libertad. Parece que la opinión pública (y muchos expertos jurídicos y económicos) se decanta en su mayoría por la libertad, mientras que los expertos sanitarios optan más por la salud pública o sanitaria. No obstante, que prime la salud pública (seguridad) no implica que todo valga desde la óptica jurídico-constitucional, ni que el fin justifique los medios.

${ }^{95}$ MONTOYA MELGAR, A., "Para una revisión de los límites del derecho de huelga". Revista del Instituto de Estudios Económicos, núms. 2-3, 2010 (Ejemplar dedicado a: La regulación del derecho de huelga en España), p. 3.

96 APARICIO DE LÁZARO, J. R., "Los estados de alarma y excepción como mecanismos legales ante una pandemia”, op. cit., pp. 27 y 28. 